\title{
Maternity services: the shaping of things to come
}

\author{
Luisa Dillner
}

Almost half of us will give birth and most of the rest of us will watch. It should therefore come as no surprise that doctors are not the only ones to hold strong views on maternity care. A conference held at the Royal Society of Medicine last month brought together obstetricians, economists, general practitioners, midwives, and representatives from consumer groups to determine how obstetric policy is made and how change can be achieved.

The conference, which last met 10 years ago, picked an exciting time to reconvene-a time of immense upheaval in the health service, with NHS reforms promoting community based care. The conference soon raised the question of whether there are any obstetric services left in the community to build on Only $1 \%$ of births in Britain will take place at home this year, and most of these will occur by accident rather than design. A further $9 \%$ of births will take place in general practitioner units. From the 1950 s maternity services have been firmly incorporated into hospitals. The centralisation of this intrinsically common and healthy event has been almost complete.

It is the experts-particularly obstetricians and paediatricians - who have led obstetric care out of the community and into the hospitals, and they have had most of the say in policy making on most maternity issues. Recently, government select committees and consumer groups have also become more influential. Research has had only a limited impact on policy making, and all these influences look set to be dwarfed by the impact of the NHS reforms.

\section{The experts' view - pregnancy is safe only in retrospect}

Successive government committees have interpreted expert advice to mean that a safe birth is a hospital birth. They have placed more weight on the opinion of obstetricians than midwives and general practitioners. The 1970 Peel committee reported, "We think that sufficient facilities should be provided for $100 \%$ hospital delivery. The greater safety of hospital confinement for mother and child justifies this objective."

As recently as 1984 the Maternity Services Advisory Committee attributed the dramatic reduction in stillbirths and neonatal deaths to the practice of delivering nearly all babies in hospital. Even the Association for Improvements in the Maternity Services (AIMS), a consumer pressure group, convinced by these arguments, lobbied for women's rights to specialist care. The research evidence does not unequivocally support the policy of all babies being born in hospital, and nor does it provide adequate guidance on what is optimal in many other aspects of maternity care. Thus the number of antenatal visits varies from five in Switzerland to 14 in Sweden, and caesarean section rates vary widely from country to country. The experts cannot determine policy alone.

British Medical Journal, London WC1H 9JR

Luisa Dillner, FRCS, editorial registrar

BMF 1991;302:1198-200 ing to Ann Oakley, director of the University of London's Social Science Research Unit, the 1980s was the decade of the consumer. "People began protesting at induction rates and this spread to a complaint about the dominance of the medical model of childbirth. Women didn't like the model of pregnancy as pathology - needing institutionalisation-so maternity care pressure groups sprang up. These groups receive some government funding so it is seen as right that a woman should be able to speak out about maternity care. Ann Cartwright's study of induction in 1979 showed that all classes of women felt the same about the poor communication with doctors. The only difference between the classes was that working class women were not asked how they felt. There is still no regular monitoring of women's satisfaction with maternity services."

Through the Maternity Services Liaison Committees, set up in the late 1980 s, women were meant to have a voice through which they could influence the decisions of health authorities. Mary Newburn of the National Childbirth Trust spoke of these multidisciplinary groups being dominated by doctors and managers discussing esoteric issues. "Often the person representing the consumer has only their own experience as a parent to argue from. They are not taken seriously. The consumers need to be educated, to have access to audit and research findings before they can participate."

It is not only women who are considered to be the consumers of maternity care. A new fetal rights movement, particularly strong in the United States, puts the safety of the fetus above maternal choice in pregnancy. Women in the United States have been prosecuted for harming their babies by drinking alcohol and taking cocaine. As the sociologist Barbara

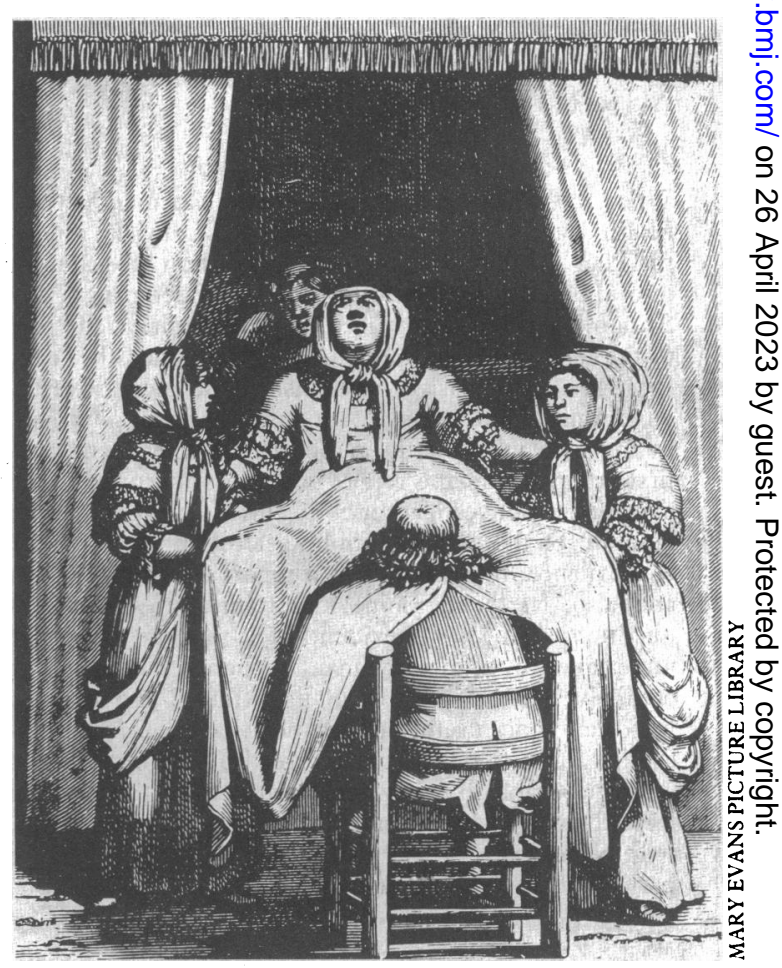

Home birth in the 17th century. Not a cosy experience

\section{What the consumers want}

Over the past decade women have become more inclined to make their own decisions about pregnancy care. AIMS now campaigns for women to have the choice of delivering outside of specialist units. Accord-

Hod




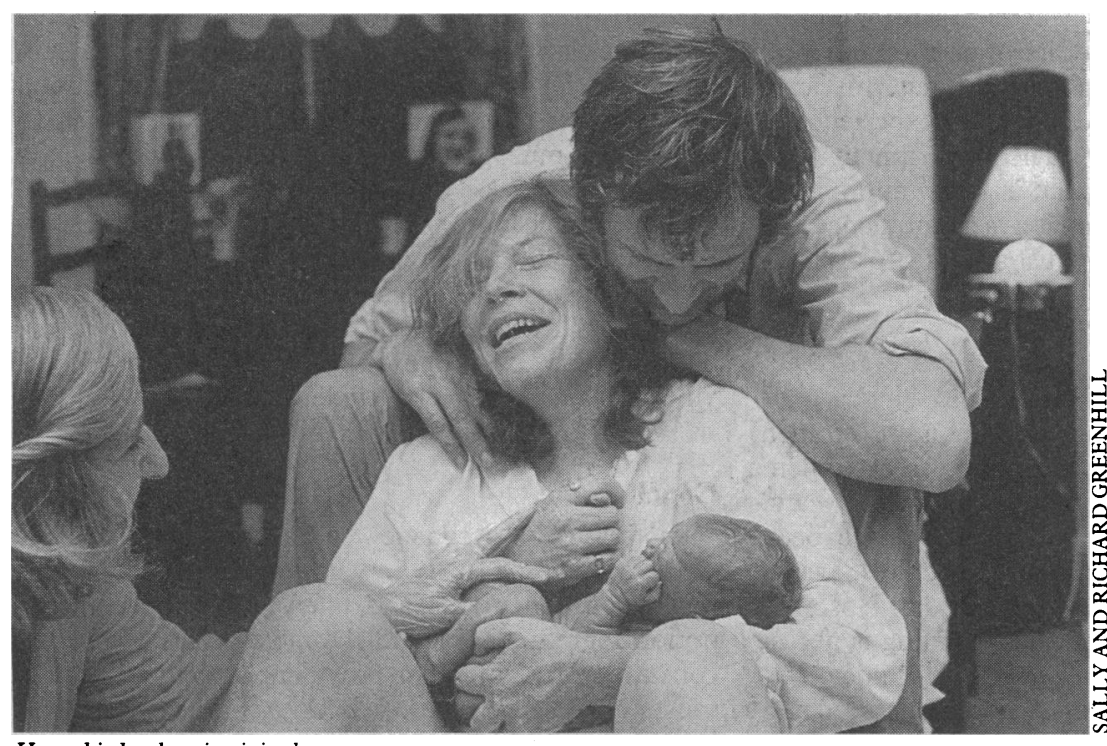

Home birth-keeping it in the family in the 1990's

Katz Rothman wrote, "Pregnant women [become] the unskilled workers on a reproductive assembly line."

\section{Research and changes in policy}

Rarely does research evidence show clearly what constitutes the best care in pregnancy. This is because to pick up bad outcomes - which are fortunately rare requires trials including hundreds of thousands of women. Obstetricians often think it unethical to randomise the type of care that women receive. Also, it is difficult to quantify maternal feelings of satisfaction and wellbeing, which consumers would argue are important measures on which to plan pregnancy care. According to Chris Ham, a fellow in health policy at the King's Fund College, research is largely ignored by policy makers. "Rational argument and research evidence by themselves will not shape policy. They have to have a political force before they can influence the development of services. There is no relationship between quality of research and its impact on policy. The Black report, which was a piece of good research showing the inequalities of health, was brought into a hostile environment and had little impact."

\section{NHS reforms and the concept of rationing}

In Chris Ham's opinion the most important changes in policy will almost certainly arise out of the separation of purchaser and provider responsibilities in the new NHS. "The reforms will not go away," he warned. "We must use them as an opportunity to change maternity practices."

For the first two years block contracts will largely prevail; purchasers will be learning to identify the best ways of spending money. Once district health authorities negotiate contracts they will become accountable to the public and professionals for their allocation of resources. The amount of money set aside for extracontractual health care will determine the amount of choice available.

Professor Alan Maynard of the University of York's department of health economics believes that district health authorities will make efficiency a priority. "For the purchasers to be efficient, they need to minimise the cost of giving a particular level of outcome," explained Professor Maynard. "It is difficult to get sensible pricing data from contracts, and there are enormous variations in prices and ways of judging quality. We already ration our resources, often indefensibly in the light of evidence. Purchasers will have to make explicit choices, shown up in contracts, and then have to defend their decisions."
One way of rationing resources is being explored in Oregon. ${ }^{1}$ The proposal is to ration care for those on Medicaid by ranking all medical interventions in terms of benefit and cost. "Access to services would be determined by whether that service is proven to improve people's health," stated Professor Maynard. "Oregon has recently published its second list of interventions which include obstetric services. Prioritising took into account the best guesses of experts, a survey of the literature, and a telephone poll of the local community trying to get their evaluation of procedures."

Professor Maynard says that this rationing is very explicit. "There will be a cut off point at 400 or 500 , above which Medicaid will not reimburse people for care they receive. Whereas caring for a low birthweight baby of $1250 \mathrm{~g}$ ranks number 18 , a baby under $500 \mathrm{~g}$ carries number 713 . There is a temptation to use the Oregon ranking system, but it is more a political than a scientific activity."

\section{Matching staff skills to activities}

District health authorities may not be quite so radical in their rationing, but they may make radical economies in their staffing. If the desired outcome in pregnancy care is a live mother and baby then providing consultant care for most of them will involve paying over the odds. Rosemary Jenkins, a midwife and adviser to the select committee that will report on the first part of its inquiry into maternity services in July, believes that in contemplating the appointment of new health care assistants the government is keen to employ the least expertise needed to obtain a good outcome.

"Staffing consumes the highest percentage of health expenditure," she argued, "and it is important to match the level of ability to the health care need. Perinatal mortality rates cannot give us information on who is the right person to do a particular job. So far maternity care has functioned as an emergency service. The cuts have left it relatively unscathed. This will not continue. The market leader in pregnancy care will be the package offering community based care and continuity of carer."

\section{Preserving the freedom to choose: do GPs still have a role?}

General practitioners are well suited to offer both community based and continuous pregnancy care, but they may not want to. General practitioners' commitment to pregnancy care has been eroded by lack of financial incentives and anecdotal evidence on the risks of intrapartum care, which has shut some general practitioner units.

According to Gavin Young, a general practitioner practising obstetrics in Penrith, the perinatal mortality rate for isolated general practitioner units is $5 \cdot 1$ per 1000 , including transfers in labour. This compares with a national figure of $9 \cdot 5$ per 1000 . "Many obstetricians ignore all the epidemiological data from Holland, where community based birth is a common event, and insist it is not safe for women," he argues. "Results for GP units are good. Safety is not the only factor in the equation. A woman's sense of wellbeing has an important effect on outcome. We know it is safer to travel to Edinburgh by train than by car, but we do not close the Al. The issue is whether the place of birth is safe enough. We should not ban women from making that choice."

Dr Peter Kielty, past chairman of the maternity services subcommittee, believes that antiquated fees, which do not reflect the responsibilities of intrapartum care, and inappropriate training of senior 
house officers have put many general practitioners off. "GP trainees are reared on a diet of abnormality and fear. It's surprising they are not put off maternity care for life," he said. "GPs do not have the experience of helping midwives at home. The government may decide that a medical component in the community is unnecessary - all that is needed is a fast ambulance and an open road. It will probably just ask GPs to do their best."

\section{Encouraging the obstetricians}

Consumer groups would also like more women obstetricians. Only $12 \%$ of consultants are women. The percentage has remained unchanged for 25 years. Recently, obstetric training programmes have been undersubscribed by both sexes. To Wendy Savage, consultant obstetrician at the Royal London Hospital, this means that the restructuring of training is necessary. "It can take 13 years to reach consultancy. We should shorten it to six, making it more structured and geographically based so married couples know where they will be for the next few years," she said. "We need more psychological input so that we develop doctors who can talk to women. We must get away from the myth that trainees will learn enough if we extend their training for long enough."

\section{How to implement change}

If consumers and providers want more choice in maternity care they will have to influence the purchasers. Barbara Stocking, director of the King's Fund Centre, spoke of the need to adopt a variety of methods to change practices. "It is not enough to feed information back to people," she explains, "you have to exert peer pressure through audit and external incentives in the way the government has done in providing GPs with immunisation targets. Opinion leaders must be convinced to change their practice. Consumers must get hold of research on which to base their case.

"It is important to involve people and to remove the stumbling blocks. Often people feel insecure about changes at work. They need to know how it will affect them-for instance, will it mean they go home later? They may need retraining. People need to be convinced to base practice on evidence."

\section{Conclusions}

In the 1990s pregnancy care looks set to become more community based, with continuity of care a major component. This is likely to be the cheapest option for purchasers and the most desirable one for consumer groups. What providers of pregnancy care must ensure is that there is back up in the community in case things go wrong. This may mean that midwives must become skilled in resuscitating the newborn and that general practitioners should make themselves available to attend midwife deliveries.

The public have a high expectation of pregnancy care. The results of bad outcomes will doubtless continue to result in litigation. It is the fear of litigation that encourages intervention on the part of some obstetricians and discourages some midwives from taking responsibility. Whatever happens in the future, it will not take many maternal or perinatal deaths in the community to send pregnancy care back into the hospitals.

1 Klein R. On the Oregon trail: rationing health care. BMf 1991;302:1-2.

\title{
Lesson of the Week
}

\section{Inhalation of baby powder: an unappreciated hazard}

\author{
P W Pairaudeau, R G Wilson, M A Hall, M Milne
}

Talcum powder can cause severe respiratory symptoms in infants; its use should be discouraged and containers should carry a warning and have child proof caps

Southampton General Hospital, Southampton SO9 4XY

$\mathrm{P}$ W Pairaudeau, MRCP, lecturer in child health M A Hall, MRCP, consultant paediatrician

M Milne, FCANAES, registrar in anaesthetics

Odstock Hospital,

Salisbury SP2 8BJ

$\mathrm{R} \mathrm{G}$ Wilson, $\mathrm{MB}$, registrar in paediatrics

Correspondence to: Dr Pairaudeau.

BMF 1991;302:1200-1
The use of talcum powder is part of the traditional care of infants. We report an incident in which accidental inhalation of baby powder caused severe respiratory difficulties and highlight the potential risks of this practice.

\section{Case report}

A previously well 12 week old boy inadvertently had baby talcum powder spilt on his face when the container was inverted during a nappy change. He was noted to cough and choke immediately and attempts were made to remove all visible powder deposited in his mouth. He subsequently refused to feed and vomited once.

Four hours later he was admitted to hospital with severe respiratory difficulties; he was centrally cyanosed, grunting, and tachypnoeic and coarse crepitations were audible throughout both lung fields. Analysis of arterial gases showed mixed acidosis $\left(\mathrm{pH} \mathrm{7.09,} \mathrm{PaCO}_{2}\right.$ $9.95 \mathrm{kPa}, \mathrm{PaO}_{2} 14.4 \mathrm{kPa}$, bicarbonate concentration $17 \cdot 1 \mathrm{mmol} / \mathrm{l}$; and base excess $-9.4 \mathrm{mmol} / \mathrm{l}$ ) in $60 \%$ facial oxygen. His condition deteriorated 30 minutes after his admission, culminating in a respiratory arrest. Endotracheal intubation was quickly accomplished, but he vomited a quantity of white talc-like material shortly after the airway was secured.

After he was transferred to the intensive care unit at
Southampton chest radiography showed that the right main bronchus had been intubated. The left lung was collapsed but reaeration was shown 34 hours after intubation. The right lung showed significant and persistent radiological changes. Subsequent ventilation with paralysis and sedation was uneventful; steroids were commenced intravenously and bronchoscopy the following day gave normal results. He was extubated three days later and on follow up at four months remained well, although some intermittent wheezing persisted. There was a family history of asthma.

\section{Discussion}

Talcum powder consists of finely ground magnesium silicate; zinc and magnesium stearate may be present as well. The therapeutic use of talc in the pleural cavity and the pulmonary effects of long term industria exposure are well described. ${ }^{1}$

Thirty cases of symptomatic talcum powder inhalation, occurring predominantly in infants and preschool children, have been described (including this case). Eight deaths have been attributed to inhalation of baby powder, ${ }^{2-6}$ and many household incidents associated with baby powders have been reported to poison centres (table), accounting for up to $1 \%$ of all calls concerning children under 5 years. ${ }^{3}$ Many inhalation incidents have been reported to have 